\title{
EFEITO DE ESCARIFICAÇÃO E DA EROSIVIDADE DE CHUVAS SOBRE ALGUMAS VARIÁVEIS DE VALORES DE EROSÃO HÍDRICA EM SISTEMAS DE MANEJO DE UM NITOSSOLO HÁPLICO(1)
}

\author{
Ildegardis Bertol ${ }^{(2)}$, Wilson Antonio Zoldan Junior ${ }^{(3)}$, Evandro Luiz \\ Fabian $^{(4)}$, Eduardo Zavaschi ${ }^{(4)}$, Rafael Pegoraro ${ }^{(4)} \&$ \\ Antonio Paz González ${ }^{(5)}$
}

\begin{abstract}
RESUMO
O preparo do solo altera as suas condições físicas de superfície e subsuperfície e, conseqüentemente, influencia os valores de propriedades que se relacionam com a erosão hídrica. O trabalho, realizado entre junho de 2005 e março de 2006 em um Nitossolo Háplico alumínico típico, objetivou estudar o efeito de uma escarificação e da erosividade de chuvas sobre algumas variáveis relacionadas à erosão hídrica do solo nos sistemas de manejo: (a) preparo convencional sem cultivo do solo (SCE); (b) preparo convencional (PCE); (c) semeadura direta em solo nunca preparado e com resíduos queimados (SQE); e (d) semeadura direta tradicional (STE). Nos tratamentos PCE, SQE e STE, cultivaram-se aveia-preta, soja, ervilhacacomum, milho, feijão preto, nabo forrageiro, em rotação durante cinco anos e meio. Após a escarificação, aplicaram-se cinco testes de chuva simulada, com $64 \mathrm{~mm} \mathrm{~h}^{-1}$ e duração de 20, 30, 40, 50 e 60 min cada um. Entre os testes 2 e 3 de chuva simulada, ocorreram $57 \mathrm{~mm}$ de chuva natural; entre os testes 3 e 4,21 mm; e entre os testes 4 e $5,30 \mathrm{~mm}$. Determinaram-se o teor de água no solo antes das chuvas, a rugosidade superficial do solo, o tempo de empoçamento e de início da enxurrada, a infiltração de água no solo, o escoamento superficial, a concentração de sedimentos na enxurrada e a perda total de solo. $O$ teor de água do solo praticamente não variou
\end{abstract}

\footnotetext{
(1) Parte da Tese de Mestrado do segundo autor. Recebido para publicação em abril de 2007 e aprovado em novembro de 2007.

(2) Professor do Departamento de Solos, Faculdade de Agronomia, Universidade do Estado de Santa Catarina - CAV/UDESC. Caixa Postal 281, CEP 88520-000 Lages (SC). Bolsista do CNPq. E-mail: a2ib@cav.udesc.br

${ }^{(3)}$ Mestrando do Departamento de Solos, CAV/UDESC. Bolsista do PROMOP. E-mail: a6wazj@cav.udesc.br

(4) Aluno do Curso de Agronomia, CAV/UDESC. Bolsista de Iniciação Científica do CNPq.

(5) Catedrático de Edafologia y Química Agrícola da Universidade da Coruña, UDC, Espanha; E-mail: tucho@udc.es
} 
nos tratamentos e nos testes de chuva. A rugosidade superficial foi influenciada pelo manejo anterior do solo, tendo sido menor no SCE do que nos demais tratamentos, sem diferença entre estes. Ao final dos testes de chuva, a rugosidade superficial era menor do que antes do seu início em todos os tratamentos, com exceção do SCE. Esse comportamento da rugosidade influenciou o empoçamento da água da chuva na superfície do solo e, principalmente, o início da enxurrada, refletindo-se também na infiltração de água no solo e no volume de enxurrada. $O$ tratamento STE foi o mais eficaz na redução do volume de enxurrada, na concentração de sedimentos na enxurrada e na perda total de solo. $O$ modelo exponencial do tipo $\mathrm{y}=\mathrm{a} \mathrm{e}^{-\mathrm{bx}}$ ajustou-se à taxa de perda de solo e à erosividade das chuvas no tratamento SCE, enquanto em PCE, SQE e STE foi o modelo linear do tipo $y=a+b x$ que se ajustou aos referidos dados.

Termos de indexação: chuva simulada, rugosidade, enxurrada, perda de solo.

\title{
SUMMARY: EFFECT OF CHISELING AND RAINFALL EROSIVITY ON SOME CHARACTERISTICS OF WATER EROSION IN A NITOSOL UNDER DISTINCT MANAGEMENT SYSTEMS
}

\begin{abstract}
Tillage changes the physical conditions of the soil surface and subsurface and, consequently, influences values of the parameters related to water erosion. This study aimed to determine, from June 2005 to March 2006, the effect of a chiseling operation and of the rainfall erosivity on some parameters related to the soil water erosion in a Nitosol under the following soil management systems: (a) conventional tillage without soil cultivation (BSE), (b) conventional tillage (CTE), (c) no-tillage in never-tilled soil and with burned crop residue (NQE), and (d) traditional no-tillage (NTE). In CTE, NQE and NTE treatments, black oat, soybean, vetch, corn, oat, bean, fodder radish, soybean, vetch, corn and oat were cropped in rotation during five and a half years. After chiseling, five rainfall tests were simulated (intensity of $64 \mathrm{~mm} \mathrm{~h}^{-1}$ ) during 20, 30, 40, 50 and $60 \mathrm{~min}$. Between the second and third test there was $57 \mathrm{~mm}$ natural rainfall, $21 \mathrm{~mm}$ between the third and fourth test, and $30 \mathrm{~mm}$ between the fourth and fifth test. Soil moisture content, surface roughness, time of puddle formation and the beginning of runoff, soil water infiltration, total runoff, sediment concentration in runoff, and total soil loss were determined prior to each rainfall test. There was virtually no variation in soil water content in the treatments and rainfall tests. The surface roughness was influenced by the previous soil management and was lower in BSE than in the other treatments, which did not differ from each other. At the end of the rainfall tests, the soil surface roughness was lower than at the beginning in all treatments, except in BSE. This roughness pattern influenced the puddling of rainfall water on the soil surface, and especially the beginning of runoff, and affected the soil water infiltration and runoff volume. The NTE treatment was the most effective to reduce the runoff volume, sediment concentration in the runoff and total soil loss. The exponential model $\left(y=a e^{-b x}\right)$ was adjusted to soil loss and rainfall erosivity data for the soil without cultivation. Data from the soil under conventional soil tillage, no-tillage with residue burning and no-tillage with residue maintenance, it was adjusted a linear model $(y=$ $a+b x)$.
\end{abstract}

Index terms: simulated rainfall, roughness, runoff, soil loss.

\section{INTRODUÇÃO}

As propriedades físicas de superfície e subsuperfície e a cobertura do solo são alteradas pelo preparo mecânico e influenciam a erosão hídrica pluvial. A densidade, rugosidade e porosidade do solo são as propriedades de superfície mais prontamente alteradas pelo preparo, enquanto, na subsuperfície, tal alteração se restringe à densidade e porosidade do solo.
O preparo do solo efetuado com uma escarificação resulta em maior rugosidade, porosidade e cobertura superficial do que quando esse método é seguido de gradagem e também maior do que quando é feita uma aração seguida de gradagens. Esse método, por sua vez, acarreta maior rugosidade e porosidade e menor cobertura superficial do solo do que a semeadura direta, pois o preparo é efetuado somente na linha de semeadura (Bertol et al., 1997; Schick et al., 2000; 
Bertol et al., 2007). Abaixo da camada de solo preparada, a densidade e porosidade são pouco influenciadas pela escarificação seguida de gradagem e pela semeadura direta, enquanto, na aração seguida de gradagens, ocorre considerável aumento de densidade e diminuição da porosidade (Cavalieri et al., 2006; Marcolan \& Anghinoni, 2006).

Dentre as variáveis primárias que influenciam a erosão hídrica do solo, a cobertura e a rugosidade superficial são as mais importantes, sendo responsáveis por quase toda a armazenagem de água e retenção de sedimentos da erosão na superfície do solo (Cogo, 1981; Onstad, 1984; Kamphorst et al., 2000). A água armazenada na superfície tem mais tempo para infiltrar no solo e o tempo de escoamento superficial é menor, refletindo-se em menor volume de enxurrada (Schwab et al., 1993). O aumento da rugosidade superficial aumenta o tempo de empoçamento na superfície e retarda o início e o pico do escoamento (Zoldan Junior, 2006; Bertol et al., 2007). O tempo necessário para a água empossar na superfície do solo, iniciar o escoamento e atingir o seu pico é fundamental para definir as características do hidrograma (Schwab et al., 1993). Essas variáveis hidráulicas são influenciadas especialmente pela rugosidade e porosidade superficiais, dependentes principalmente do preparo do solo (Cogo et al., 1984). Assim, o retardamento do início do escoamento, em decorrência do empoçamento da água na superfície do solo, dentre outros fatores, e o retardamento do tempo de equilíbrio da enxurrada, em decorrência do seu crescimento mais lento, resultam em redução do volume e da taxa máxima da enxurrada e em diminuição das perdas de solo por erosão hídrica (Cogo et al., 1984).

A infiltração de água no solo aumenta e a enxurrada diminui em superfícies rugosas de solo e, ou, cobertas em relação a superfícies lisas e, ou, descobertas. Em decorrência disso, superfícies rugosas de solo e parcialmente cobertas, como ocorre na escarificação seguida de gradagem, são mais eficazes na redução da erosão hídrica do que superfícies rugosas e descobertas, como se observa na aração seguida de gradagens (Cogo et al., 1984). O escoamento de água da chuva em superfície de solo com grande rugosidade apresenta menor carga de sedimentos do que nas menos rugosas, resultando em menor perda total de solo (Cogo et al., 1984). Ainda, a taxa de perda de solo tende a aumentar com o aumento da erosividade da chuva, especialmente em solos degradados por arações e gradagens por longo tempo (Zoldan Junior, 2006).

O objetivo deste trabalho foi avaliar algumas características de erosão hídrica do solo resultante da aplicação de chuvas simuladas em solo rugoso. A rugosidade foi criada por escarificação efetuada em distintos sistemas de manejo do solo cultivado por cinco anos e meio.

\section{MATERIAL E MÉTODOS}

O trabalho foi realizado entre junho de 2005 e março de 2006, em São José do Cerrito, SC, entre as coordenadas $28^{\circ} 55^{\prime} 44^{\prime \prime}$ latitude sul e $51^{\circ} 08^{\prime} 32$ " longitude, a oeste de Greenwich. O clima é do tipo $\mathrm{Cfb}$ (subtropical úmido), segundo a classificação de Köeppen, e a altitude média é de $846 \mathrm{~m}$. O solo no local do experimento é um Nitossolo Háplico alumínico típico. Na camada de $0-0,2 \mathrm{~m}$, o solo apresentou $118 \mathrm{~g} \mathrm{~kg}^{-1}$ de areia, $255 \mathrm{~g} \mathrm{~kg}^{-1}$ de silte e $627 \mathrm{~g} \mathrm{~kg}^{-1} \mathrm{de}$ argila total. A argila dispersa em água foi de $94 \mathrm{~g} \mathrm{~kg}^{-1}$, a densidade de partículas, de $2,8 \mathrm{~g} \mathrm{~cm}^{-3}$, e o C orgânico, de $32 \mathrm{~g} \mathrm{~kg}^{-1}$. A declividade média das parcelas experimentais era de $0,17 \mathrm{~m} \mathrm{~m}^{-1}$. Nos tratamentos (descritos adiante), a declividade era de $0,18 \mathrm{~m} \mathrm{~m}^{-1}$ no $\mathrm{SCE}, 0,16 \mathrm{~m} \mathrm{~m}^{-1}$ no PCE, $0,20 \mathrm{~m} \mathrm{~m}^{-1}$ no SQE e $0,14 \mathrm{~m} \mathrm{~m}^{-1}$ no STE.

A unidade experimental, ou parcela, media $3,5 \mathrm{~m}$ de largura por 11,0 $\mathrm{m}$ de comprimento, no sentido paralelo ao declive, limitada na extremidade superior e nas laterais por chapas galvanizadas com $0,2 \mathrm{~m}$ de altura e cravadas $0,1 \mathrm{~m}$ no solo. A extremidade inferior era delimitada por uma calha coletora de enxurrada, que, conectada a um tubo de PVC, a conduzia até o local de coleta, situado $6 \mathrm{~m}$ abaixo dela. Foram utilizadas oito parcelas.

A pesquisa foi realizada em campo, com chuva simulada por um simulador de braços rotativos (Figura 1), que cobria simultaneamente duas parcelas experimentais, distanciadas entre si de $3,5 \mathrm{~m}$ (Swanson, 1965), com intensidade de chuva planejada de $64 \mathrm{~mm} \mathrm{~h}^{-1}$.

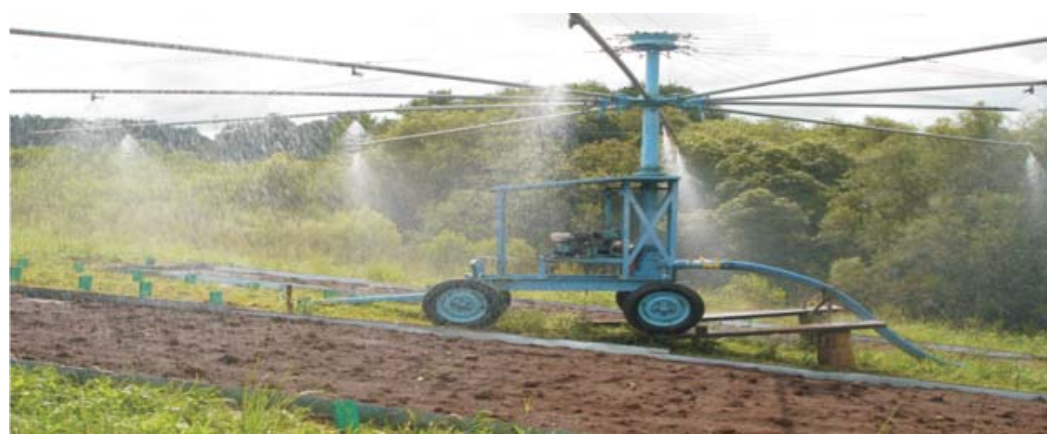

Figura 1. Simulador de chuvas em operação. 
Os tratamentos de manejo do solo estudados, em duas repetições, distribuídos ao acaso, foram preparo convencional sem cultivo do solo durante cinco anos e meio. Foram feitas uma aração a $0,20 \mathrm{~m}$ e duas gradagens a $0,15 \mathrm{~m}$ de profundidade no sentido paralelo ao declive, duas vezes ao ano, além de escarificações manuais. Nos últimos seis meses, o solo permaneceu sem preparo, apenas com capinas e escarificações manuais. A superfície do solo foi mantida livre de vegetação e de crosta superficial durante cinco anos e meio. No final desse período, foram feitas uma escarificação mecânica (SCE); preparo convencional com cultivo do solo durante cinco anos e meio. Fez-se uma aração a $0,20 \mathrm{~m}$ e duas gradagens a $0,15 \mathrm{~m}$ de profundidade duas vezes ao ano. Os resíduos culturais foram incorporados ao solo durante cinco anos, e o de aveia, mantido na superfície do solo durante o último cultivo, foi, ao final deste, retirado, fazendo-se uma escarificação mecânica (PCE); semeadura direta em campo natural cultivado sem preparo do solo durante cinco anos e meio. Os resíduos vegetais do campo (antes do primeiro cultivo) e das culturas (após os demais cultivos) foram queimados. Assim, ao final do último cultivo, queimou-se o resíduo cultural de aveia e fez-se uma escarificação mecânica (SQE) e semeadura direta a partir do segundo cultivo do solo, implantada sobre preparo convencional efetuado no momento da instalação da área experimental (primeiro cultivo há cinco anos e meio), denominada semeadura direta tradicional. Os resíduos culturais foram mantidos na superfície do solo. Ao final do último cultivo, retirou-se o resíduo cultural de aveia da superfície do solo e fez-se uma escarificação mecânica (STE). Nos tratamentos PCE, SQE e STE, cultivaram-se aveiapreta (Avena strigosa), soja (Glycine max), ervilhacacomum (Vicia sativa), milho (Zea mays), aveia-preta, feijão preto (Phaseollus vulgaris), nabo forrageiro (Raphanus sativus), soja, ervilhaca-comum, milho e aveia-preta. A retirada do resíduo de aveia dos tratamentos PCE e STE e a queima dele no SQE foram realizadas em 11 de janeiro de 2006. A escarificação foi efetuada em 12 de janeiro de 2006, sobre o solo com teor de água aproximadamente no ponto de friabilidade e descoberto. O escarificador, acionado por trator no sentido paralelo ao declive, possuía 13 hastes distanciadas $0,25 \mathrm{~m}$ uma das outras, que trabalharam a uma profundidade de $0,18 \mathrm{~m}$.

Foram efetuados cinco testes de chuva simulada sobre os tratamentos, com chuvas de intensidade constante. Entre testes e entre tratamentos, houve variação de intensidade das chuvas. No teste 1, elas variaram de 61 a $66 \mathrm{~mm} \mathrm{~h}^{-1}$, e no teste 2 , de 76 a $81 \mathrm{~mm} \mathrm{~h}^{-1}$. No teste 3 , a variação foi de 68 a $73 \mathrm{~mm} \mathrm{~h}^{-1}$, enquanto no teste 4 foi de 70 a $73 \mathrm{~mm} \mathrm{~h}^{-1}$ e, no teste 5 , de 68 a $78 \mathrm{~mm} \mathrm{~h}^{-1}$. Os testes de chuva apresentaram durações variáveis, como a seguir descrito: primeiro teste, realizado um dia após a escarificação do solo (12/1/ 2006), com 20 min de chuva; segundo teste, realizado quatro dias após o primeiro (16/1/2006), com $30 \mathrm{~min}$ de chuva; terceiro teste, realizado sete dias após o segundo (23/1/2006), com 40 min de chuva; quarto teste, realizado nove dias após o terceiro (1/2/2006), com $50 \mathrm{~min}$; e, quinto teste, realizado seis dias após o quarto (7/2/2006), com 60 min de chuva. A erosividade das chuvas simuladas, calculada com base no método de Meyer (1958), variou entre os tratamentos. A variação foi de 256 a $302 \mathrm{MJ} \mathrm{mm} \mathrm{ha}^{-1} \mathrm{~h}^{-1}$ no teste 1; de 609 a $686 \mathrm{MJ} \mathrm{mm} \mathrm{ha}^{-1} \mathrm{~h}^{-1}$ no teste 2; de 624 a $747 \mathrm{MJ} \mathrm{mm} \mathrm{ha}^{-1} \mathrm{~h}^{-1}$ no teste 3 ; de 849 a $917 \mathrm{MJ} \mathrm{mm} \mathrm{ha-1} \mathrm{h}^{-1}$ no teste 4 ; e de 950 a $1.272 \mathrm{MJ} \mathrm{mm} \mathrm{ha}^{-1} \mathrm{~h}^{-1}$ no teste 5 . Imediatamente antes da realização de cada simulação de chuva, coletaram-se amostras do solo nas profundidades de 0 0,1 e 0,1-0,2 m, para quantificar o teor de água.

A superfície do solo permaneceu descoberta durante o período experimental e, no intervalo de algumas chuvas simuladas, ocorreram chuvas naturais. Entre a segunda e a terceira chuva, houve precipitação pluvial de $57 \mathrm{~mm}$, sendo $50 \mathrm{~mm}$ no dia 18/1/2006 e $7 \mathrm{~mm}$ no dia 22/1/2006. Entre a terceira e a quarta chuva, a precipitação pluvial foi de $21 \mathrm{~mm}$ no dia $31 / 1 / 2006$ e, entre a quarta e a quinta, de $30 \mathrm{~mm}$ no dia 6/2/2006.

A rugosidade superficial do solo foi avaliada imediatamente antes e após o preparo do solo com escarificador e imediatamente após os testes de chuva simulada. Para efetuar as leituras do microrrelevo superficial, utilizou-se um rugosímetro contendo 20 varetas de $\mathrm{Al}$, com uma câmara fotográfica digital acoplada (Figura 2), descrito em Zoldan Junior (2006), que possibilitou a leitura de 400 pontos de altura da superfície do solo em cada parcela, numa área de amostragem de $0,36 \mathrm{~m}^{2}(0,6 \times 0,6 \mathrm{~m})$. A rugosidade ao acaso da superfície do solo foi calculada pelo método proposto por Kamphorst et al. (2000).

Durante a simulação das chuvas, foram anotados o tempo de empoçamento da água de enxurrada na superfície do solo e o tempo necessário para a enxurrada iniciar-se.

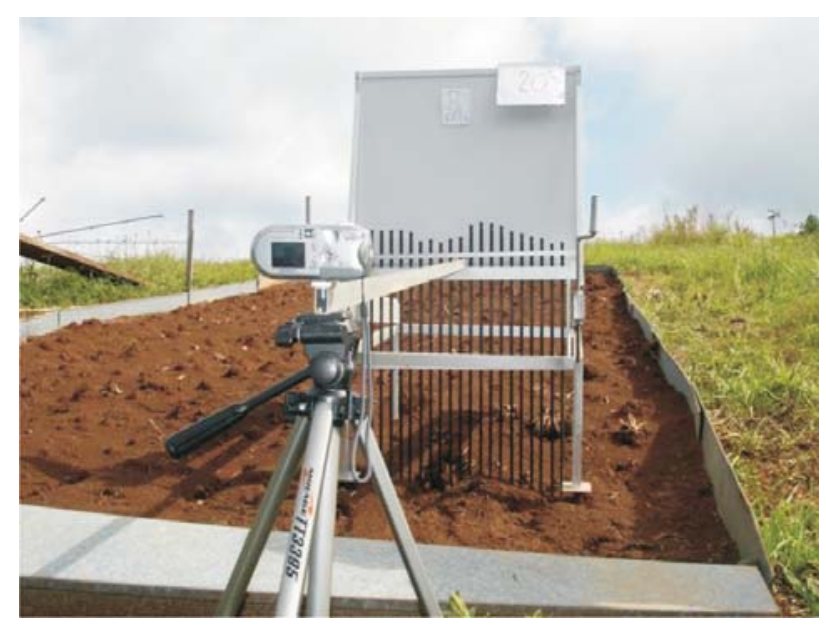

Figura 2. Rugosímetro em operação. 
Enquanto acontecia a enxurrada, foram coletadas amostras dessa água e feitas medições de sua taxa de descarga intermitentemente a cada três minutos. Posteriormente, em laboratório, determinou-se a concentração de sedimentos na enxurrada e calcularam-se a taxa de infiltração de água no solo, o volume de escoamento superficial e a perda total de solo. O volume total de enxurrada observada foi ajustado para a intensidade de chuva planejada de $64 \mathrm{~mm} \mathrm{~h}^{-1}$, em decorrência de ter ocorrido variação na intensidade das chuvas simuladas. Pela mesma razão, foi ajustada a perda total de solo observada e essa perda ajustada também em razão da variação da declividade das parcelas experimentais. Para a coleta das amostras de enxurrada em campo, seu processamento em laboratório, o cálculo das perdas de água e solo e o ajuste dos dados, utilizaram-se os método descritos em Cogo (1981) e Cogo et al. (1984).

A significância estatística dos efeitos dos tratamentos e das chuvas simuladas sobre algumas variáveis foi testada, quando pertinente, por meio de análise da variância. Fez-se análise comparando os tratamentos em cada teste de chuva e os testes de chuva em cada tratamento, considerando delineamento em parcelas subdivididas e as diferenças entre médias por Duncan, a $5 \%$. O modelo exponencial, $\mathrm{y}=\mathrm{a} \mathrm{e} \mathrm{e}^{-\mathrm{bx}}$, e o linear, $y=a+b x$, foram ajustados aos dados de perdas de solo relacionados aos de erosividade das chuvas.

\section{RESULTADOS E DISCUSSÃO}

\section{Teor de água no solo antes da aplicação das chuvas}

$\mathrm{O}$ teor de água no solo antecedente às chuvas simuladas estava alto em ambas as camadas do solo (Quadro 1), tendo sido maior na camada de 0,1-0,2 m do que na de $0-0,1 \mathrm{~m}$, com variações pequenas entre tratamentos, devido à ocorrência de chuvas naturais e ao pequeno intervalo entre as chuvas simuladas.

\section{Rugosidade ao acaso da superfície do solo}

A rugosidade superficial era baixa antes da escarificação (Quadro 2), semelhante aos valores encontrados por Cogo et al. (1984), Zobeck \& Onstad (1987) e Bertol et al. (2007), devido ao período de seis meses que se passou entre o último preparo e cultivo do solo e o momento em que foi iniciado este trabalho. Devido à elevada variação entre repetições $(\mathrm{CV}=$ $33,4 \%$ ), os tratamentos não diferiram naquele momento.

Após a escarificação, a rugosidade era 2,9 vezes maior do que antes da escarificação, na média dos tratamentos, tendo sido 3,7 vezes maior no SQE e STE (Quadro 2). Estes valores, em especial no SCE e PCE, foram menores do que os obtidos por Cogo et al. (1984), trabalhando com equipamento denominado "springsweep chisel" sobre um solo Hapludox típico. Também foram menores do que os obtidos em preparo do solo com equipamento denominado "chisel", no trabalho de Zobeck \& Onstad (1987) sobre um solo Hapludox.

O cultivo do solo nos tratamentos SQE, STE e PCE, durante cinco anos e meio, propiciou maior aumento de rugosidade do que a ausência de cultivo no SCE, quando foram submetidos à escarificação (Quadro 2). A diferença, na média dos tratamentos, foi de $87 \%$, o que demonstra a importância do cultivo nas propriedades físicas e na agregação do solo, de acordo com o que foi constatado por Larson \& Gill (1973). Bertol et al. (2006) encontraram relação potencial negativa significativa entre o decaimento da rugosidade ao acaso e a estabilidade dos agregados (DMP e DMG) da camada de 0-0,1 m de um Inceptisol. Assim, constata-se que, em solos fisicamente mais degradados, a rugosidade superficial decai mais rapidamente do que nos não degradados.

Quadro 1. Teor de água no solo antes da aplicação das chuvas simuladas, em sistemas de manejo submetidos à escarificação, em um Nitossolo Háplico alumínico

\begin{tabular}{|c|c|c|c|c|c|c|c|c|c|c|}
\hline \multirow{3}{*}{ Tratamento } & \multicolumn{2}{|c|}{ Teste 1} & \multicolumn{2}{|c|}{ Teste 2} & \multicolumn{2}{|c|}{ Teste 3} & \multicolumn{2}{|c|}{ Teste 4} & \multicolumn{2}{|c|}{ Teste 5} \\
\hline & \multicolumn{10}{|c|}{ Profundidade do solo, $\mathrm{cm}$} \\
\hline & $0-10$ & $10-20$ & 0-10 & $10-20$ & 0-10 & $10-20$ & 0-10 & $10-20$ & $0-10$ & $10-20$ \\
\hline SCE & 0,30 & 0,35 & 0,32 & 0,35 & 0,34 & 0,36 & 0,31 & 0,35 & 0,28 & 0,35 \\
\hline $\mathrm{PCE}$ & 0,31 & 0,35 & 0,32 & 0,35 & 0,36 & 0,36 & 0,32 & 0,36 & 0,36 & 0,38 \\
\hline $\mathrm{SQE}$ & 0,36 & 0,37 & 0,36 & 0,39 & 0,37 & 0,41 & 0,35 & 0,35 & 0,39 & 0,41 \\
\hline STE & 0,36 & 0,40 & 0,35 & 0,39 & 0,39 & 0,40 & 0,34 & 0,39 & 0,38 & 0,39 \\
\hline
\end{tabular}

SCE: solo sem cultivo submetido à escarificação; PCE: preparo convencional submetido à escarificação; SQE: semeadura direta queimada submetida à escarificação; STE: semeadura direta tradicional submetida à escarificação. 
Quadro 2. Índice de rugosidade ao acaso da superfície do solo antes (ANP) e após (APP) o preparo do solo e após os testes de chuva simulada, em sistemas de manejo submetidos à escarificação, em um Nitossolo Háplico alumínico

Tratamento
SCE
PCE
SQE

\section{STE}

$\begin{array}{llcrr} & & & \mathrm{mm} & \\ \text { ANP } & 4,2 \mathrm{Ad} & 7,7 \mathrm{Ad} & 4,9 \mathrm{Ad} & \\ \text { APP } & 9,9 \mathrm{Ba} & 16,8 \mathrm{Aa} & 18,0 \mathrm{Aa} & 20,6 \mathrm{Aa} \\ \text { AT1 } & 8,2 \mathrm{Bab} & 14,4 \mathrm{Aab} & 15,1 \mathrm{Ab} & 17,6 \mathrm{Ab} \\ \text { AT2 } & 7,6 \mathrm{Babc} & 12,0 \mathrm{Abc} & 13,9 \mathrm{Ab} & 12,9 \mathrm{Ac} \\ \text { AT3 } & 5,1 \mathrm{Bcd} & 9,6 \mathrm{Acd} & 10,6 \mathrm{Ac} & 1,9 \mathrm{Acd} \\ \text { AT4 } & 5,6 \mathrm{Bbcd} & 9,4 \mathrm{ABcd} & 9,5 \mathrm{ABc} & 11,2 \mathrm{Acd} \\ \text { AT5 } & 9,6 \mathrm{Aa} & 8,5 \mathrm{Ad} & 8,7 \mathrm{Ac} & 9,4 \mathrm{Ad}\end{array}$

SCE: solo sem cultivo submetido à escarificação; PCE: preparo convencional submetido à escarificação; SQE: semeadura direta queimada submetida à escarificação; STE: semeadura direta tradicional submetida à escarificação. AT1: após teste 1 de chuva; AT2: após teste 2; AT3: após teste 3; AT4: após teste 4; AT5: após teste 5. Médias seguidas da mesma letra, maiúscula na linha e minúscula na coluna, não diferem estatisticamente (Duncan, p < 0,05). CV para tratamento $=33,4 \%$; $\mathrm{CV}$ para teste $=10,7 \%$.

O tratamento STE propiciou tendência de aumentar a rugosidade em $23 \%$ em relação ao PCE (sem diferença estatística - Quadro 2). Em termos absolutos, isso significa acréscimo de $3,8 \mathrm{~mm}$ na rugosidade superficial no STE, ou seja, um importante ganho na capacidade de armazenagem superficial de água. Provavelmente, essa diferença foi devida à melhor estrutura do solo no STE do que no PCE, conforme verificado por Cavalieri et al. (2006) e Marcolan \& Anghinoni (2006).

As chuvas ocasionaram redução da rugosidade superficial em $54 \%$ no tratamento STE, em $52 \%$ no SQE, em 49 \% no PCE e em 7 \% no SCE, em relação aos valores anteriores (Quadro 2). A maior redução relativa da rugosidade, comparando especialmente o STE e o PCE, é explicada pelo fato de no tratamento PCE, a rugosidade inicial (antes das chuvas) ser de apenas $16,8 \mathrm{~mm}$, enquanto no STE era de $20,6 \mathrm{~mm}$. Reduções da rugosidade ao acaso pelo efeito de chuvas foram constatadas também por Cogo et al. (1984), Römkens \& Wang (1986) e Eltz \& Norton (1997).

\section{Características de enxurrada e infiltração de água no solo}

O tempo de empoçamento de enxurrada na superfície do solo diferiu nos tratamentos e testes de chuva (Quadro 3). No SQE e STE, nos dois primeiros testes de chuva simulada, com durações de 20 e $30 \mathrm{~min}$, respectivamente, e no PCE, no primeiro teste, não houve empoçamento, pois a taxa de infiltração foi superior à taxa de chuva.

Nas situações em que ocorreu empoçamento, o STE foi mais eficaz no seu retardamento, seguido do SQE (Quadro 3). A maior eficácia desses tratamentos do que os demais, nesta variável, foi devida à persistência da porosidade ao longo da ocorrência das chuvas. A melhor estrutura do solo na camada superficial desses tratamentos, constatada por Zoldan Junior (2006) neste experimento, foi responsável pela maior estabilidade dos agregados. No tratamento SCE, do segundo teste de chuva em diante, e no PCE, no último teste, o tempo de empoçamento foi curto. Isso confirma que, nesses tratamentos, o solo apresentava menor estabilidade de agregados na superfície (constatada por Zoldan Junior, 2006, neste experimento), o que propiciou selamento do solo, principalmente no SCE.

O tempo de início da enxurrada diferiu nos tratamentos estudados (Quadro 4). No teste 1 de chuva, com duração de 20 min, não ocorreu enxurrada, embora no SCE tivesse havido empoçamento aos 18 min (Quadro 3). No teste 2, com duração de 30 min, o SQE e STE não apresentaram escoamento, demonstrando elevada eficácia na infiltração de água no solo em relação aos outros dois tratamentos. Nesse teste, o SCE e PCE foram praticamente iguais em termos de tempo de início da enxurrada. Isso demonstra que, até o final do teste 2 , com $50 \mathrm{~min}$ acumulados de chuvas, o cultivo do solo no PCE não acrescentou benefício algum em relação ao não cultivo no SCE, no que se refere à variável retardamento do início da enxurrada. Outro aspecto importante a ser ressaltado é o fato de que, no SCE, o empoçamento ocorreu aos $8 \mathrm{~min}$ (Quadro 3) e o início do escoamento aos 22 min (Quadro 4), enquanto, no PCE, o empoçamento ocorreu aos 18 min e a enxurrada iníciou-se aos $23 \mathrm{~min}$. Isso revela uma vantagem do solo cultivado (PCE) em relação ao solo sem cultivo (SCE), em termos de eficácia no controle do escoamento superficial. A partir do teste 3 de chuva, o escoamento ocorreu em todos os tratamentos. Em comparação ao PCE, o STE retardou o início do escoamento em 15 min, na média dos testes 3 , 4 e 5, significando uma importante diferença no retardamento da enxurrada, 
conforme constatado também por Onstad (1984) e Kamphorst et al. (2000), e no controle do escoamento superficial, de acordo com dados obtidos também por Cogo (1981) e Bertol (1995).

No teste 1 de chuva (Quadro 5), a água infiltrou totalmente no solo em todos os tratamentos (Quadro 4), em virtude do baixo volume de chuva aplicado e da elevada rugosidade superficial (Quadro 2); no teste 2, nos tratamentos SQE e STE, a infiltração foi $15 \%$ maior do que no PCE; nos testes 3, 4 e 5, houve distintas diferenças entre tratamentos, em termos abso- lutos, na infiltração de água no solo. Assim, a STE foi 49 \% mais eficaz do que o PCE na média dos três testes de chuva, concordando com Cogo (1981) e Bertol (1995). No STE, a estabilidade dos agregados e o volume de macroporos do solo eram maiores do que no PCE, conforme demonstrado por Zoldan Junior (2006) no mesmo experimento. As diferenças entre tratamentos, no que se refere à infiltração de água no solo, tenderam a diminuir do teste 3 para o teste 5 , devido ao efeito das chuvas e enxurradas na degradação das propriedades físicas da superfície do solo e no rebaixa-

Quadro 3. Tempo de empoçamento da água de enxurrada na superfície do solo, durante os testes de chuva simulada, em sistemas de manejo submetidos à escarificação, em um Nitossolo Háplico alumínico

\begin{tabular}{|c|c|c|c|c|c|}
\hline Tratamento & Teste 1 & Teste 2 & Teste 3 & Teste 4 & Teste 5 \\
\hline $\mathrm{SCE}$ & 18 & 8 & 5 & 10 & 3 \\
\hline PCE & $>20$ & 18 & 19 & 20 & 9 \\
\hline SQE & $>20$ & $>30$ & 23 & 28 & 24 \\
\hline STE & $>20$ & $>30$ & 30 & 36 & 23 \\
\hline
\end{tabular}

SCE: solo sem cultivo submetido à escarificação; PCE: preparo convencional submetido à escarificação; SQE: semeadura direta queimada submetida à escarificação; STE: semeadura direta tradicional submetida à escarificação.

Quadro 4. Tempo de início da enxurrada, durante os testes de chuva simulada, em sistemas de manejo submetidos à escarificação, em um Nitossolo Háplico alumínico

\begin{tabular}{cccccc}
\hline \multirow{2}{*}{ Tratamento } & Teste $\mathbf{1}$ & Teste 2 & Teste 3 & Teste 4 & Teste 5 \\
\hline & & & & \\
& & & & & \\
SCE & $>20$ & 22 & 11 & 18 & 5 \\
PCE & $>20$ & 23 & 23 & 23 & 11 \\
SQE & $>20$ & $>30$ & 32 & 31 & 27 \\
STE & $>20$ & $>30$ & 40 & 30 \\
\hline
\end{tabular}

SCE: solo sem cultivo submetido à escarificação; PCE: preparo convencional submetido à escarificação; SQE: semeadura direta queimada submetida à escarificação; STE: semeadura direta tradicional submetida à escarificação.

Quadro 5. Infiltração de água no solo observada durante os testes de chuva simulada, em sistemas de manejo submetidos à escarificação, em um Nitossolo Háplico alumínico

\begin{tabular}{cccccc}
\hline Tratamento & Teste $\mathbf{1}$ & Teste 2 & Teste 3 & Teste 4 & Teste 5 \\
\hline & & & & \\
SCE & 100 & 97 & da chuva observada & 75 & 47 \\
PCE & 100 & 85 & 59 & 62 & 42 \\
SQE & 100 & 100 & 80 & 74 & 52 \\
STE & 100 & 100 & 92 & 81 & 63 \\
\hline
\end{tabular}

SCE: solo sem cultivo submetido à escarificação; PCE: preparo convencional submetido à escarificação; SQE: semeadura direta queimada submetida à escarificação; STE: semeadura direta tradicional submetida à escarificação. 
mento da rugosidade superficial (Quadro 2). No teste 5 de chuva simulada, as diferenças entre tratamentos eram relativamente pequenas, em termos de infiltração de água no solo, de acordo principalmente com as pequenas diferenças nos valores de rugosidade superficial (Quadro 2), em conformidade com dados obtidos também por Cogo (1981), Cogo et al. (1984) e Bertol (1995).

A ocorrência de escoamento superficial apenas nos tratamentos SCE e PCE, nos testes 1 e 2 (Quadro 6), foi devida ao fato de que os dados de enxurrada observados foram ajustados para a intensidade de chuva planejada de $64 \mathrm{~mm} \mathrm{~h}^{-1}$, e os dados de infiltração não foram. Nos testes seguintes de chuva, o volume de enxurrada aumentou em todos os tratamentos, com exceção do PCE, no qual a enxurrada diminuiu no teste 2 em relação ao teste 1 . O aumento da enxurrada do teste 3 para o teste 5 é explicado pelo aumento do volume das chuvas aplicadas e pela redução da rugosidade superficial do solo (Quadro 2). O STE foi o tratamento mais eficaz no controle da enxurrada, reduzindo-a em 15,5 \% em relação ao PCE e em $11 \%$ em relação ao SQE, na média dos testes 3 e 4 de chuva. Portanto, a escarificação realizada no solo sob semeadura direta foi mais eficaz no controle de enxurrada do que a realizada no solo sob preparo convencional, após ambos terem sido conduzidos durante cinco anos e meio.

\section{Concentração de sedimentos na enxurrada e perda de solo}

A concentração de sedimentos na enxurrada variou entre tratamentos e entre testes de chuva (Quadro 7) de maneira distinta. No SCE, a concentração variou de $8,48 \mathrm{~kg} \mathrm{~m}^{-3}$ no teste 2 para $74,84 \mathrm{~kg} \mathrm{~m}^{-3}$ no teste 5 , enquanto no PCE a variação foi de $4,84 \mathrm{~kg} \mathrm{~m}^{-3}$ no teste 2 para $11,22 \mathrm{~kg} \mathrm{~m}^{-3}$ no teste 5 . Essas diferenças se explicam pela diferença de resistência do solo à desagregação, já que, no SCE, o solo jamais foi cultivado durante os cinco anos e meio que antecederam o experimento, enquanto no PCE houve cultivo nesse período de tempo. Considerando o $\mathrm{SQE}$ e STE, neste último ocorreu diferença apenas do teste 4 para o teste 5 quanto à concentração de sedimentos na enxurrada, enquanto, no SQE, a diferença já ocorreu entre os testes 3 e 4 . Além disso, os sedimentos só ocorreram a partir do teste 3 de chuva nestes dois tratamentos. Isso revela a maior resistência do solo à desagregação nesses tratamentos, em especial no STE, em função do período em que o

Quadro 6. Volume de enxurrada ajustada para intensidade de chuva de $64 \mathrm{~mm} \mathrm{~h}^{-1}$, durante os testes de chuva simulada, em sistemas de manejo submetidos à escarificação, em um Nitossolo Háplico alumínico

$\begin{array}{lrrrrr}\text { SCE } & 0 & 0 & 4 & 14 & 46 \\ \text { PCE } & 0 & 0 & 38 & 26 & 39 \\ \text { SQE } & 0 & 0 & 15 & 16 & 40 \\ \text { STE } & 0 & 0 & 0 & 10 & 24\end{array}$

SCE: solo sem cultivo submetido à escarificação; PCE: preparo convencional submetido à escarificação; SQE: semeadura direta queimada submetida à escarificação; STE: semeadura direta tradicional submetida à escarificação.

Quadro 7. Concentração de sedimentos na enxurrada, durante os testes de chuva simulada, em sistemas de manejo submetidos à escarificação, em um Nitossolo Háplico alumínico

\begin{tabular}{|c|c|c|c|c|c|}
\hline Tratamento & Teste 1 & Teste 2 & Teste 3 & Teste 4 & Teste 5 \\
\hline & & & $-\mathrm{kg} \mathrm{m}^{-3}$ & & \\
\hline SCE & $0 \mathrm{Ae}$ & $8,48 \mathrm{Ad}$ & $17,83 \mathrm{Ac}$ & $32,05 \mathrm{Ab}$ & $74,84 \mathrm{Aa}$ \\
\hline $\mathrm{PCE}$ & $0 \mathrm{Ac}$ & $4,84 \mathrm{Bb}$ & $4,40 \mathrm{Cb}$ & $4,73 \mathrm{Cb}$ & $11,22 \mathrm{Ba}$ \\
\hline SQE & $0 \mathrm{Ac}$ & $0 \mathrm{Cc}$ & $9,56 \mathrm{Bb}$ & $12,09 \mathrm{Ba}$ & $11,04 \mathrm{Ba}$ \\
\hline STE & $0 \mathrm{Ac}$ & $0 \mathrm{Cc}$ & $2,03 \mathrm{Db}$ & $2,75 \mathrm{Db}$ & $5,56 \mathrm{Ca}$ \\
\hline
\end{tabular}

SCE: solo sem cultivo submetido à escarificação; PCE: preparo convencional submetido à escarificação; SQE: semeadura direta queimada submetida à escarificação; STE: semeadura direta tradicional submetida à escarificação. Médias seguidas da mesma letra, maiúscula na coluna e minúscula na linha, não diferem estatisticamente (Duncan, p < 0,05). CV para tratamento $=9,6 \%$; CV para teste $=7,2 \%$. 
solo permaneceu sem preparo. Com isso, a operação de escarificação causou mínimo distúrbio nesses tratamentos, conforme constatado também por Cogo (1981) e Cogo et al. (1984).

Entre tratamentos, houve diferença de concentração de sedimentos na enxurrada em todos os testes de chuva. No PCE, a concentração foi $81 \%$ menor do que no SCE, na média dos testes 2,3 , 4 e 5 de chuva, em função do cultivo do solo no PCE, conforme constatado também por Cogo (1981) e Cogo et al. (1984). Comparando entre si os tratamentos sob semeadura direta, a queima dos resíduos vegetais propiciou enfraquecimento da estrutura do solo (Zoldan Junior, 2006), refletindo-se em maior quantidade de sedimentos transportados pela enxurrada no SQE (queimada) do que no STE (não queimada), cuja diferença foi $68 \%$ na média dos testes 3,4 e 5 de chuva. Comparando-se os tratamentos PCE e STE, este último reduziu a concentração de sedimentos na enxurrada em 50 \% em relação ao primeiro, na média dos três últimos testes de chuva, significando importante efeito residual do manejo do solo sob semeadura direta, comparado ao preparo convencional, no que se refere à resistência do solo à erosão.

Perdas de solo só ocorreram a partir do teste 2 no SCE e PCE, e no SQE e STE a partir do teste 3, as quais aumentaram até o teste 5 , de maneira distinta nos diferentes tratamentos (Quadro 8), de acordo com os aumentos das perdas de água (Quadro 6) e das concentrações de sedimentos na enxurrada (Quadro 7), conforme constatado também por Cogo (1981) e Cogo et al. (1984). Esse comportamento se deve ao efeito combinado das perdas de água e concentrações de sedimentos na água da enxurrada. No SCE, a perda de solo aumentou 209 vezes do teste 2 para o teste 5 , enquanto, no PCE, o aumento foi de 10 vezes, diferença esta entre os tratamentos devida ao efeito do cultivo do solo. No SQE e STE, as perdas de solo aumentaram respectivamente 2,2 e 12,4 vezes, do teste 3 para o teste 5 . Essa diferença é explicada: no teste 3 , a perda de solo no STE foi baixa $\left(171 \mathrm{~kg} \mathrm{ha}^{-1}\right)$, enquanto no SQE ela foi alta $\left(1.128 \mathrm{~kg} \mathrm{ha}^{-1}\right)$, o que equivale a uma diferença de 6,6 vezes. Isso indica que a queima dos resíduos no SQE diminuiu substancialmente a resistência do solo à erosão hídrica em relação ao STE, no qual os resíduos não foram queimados. Ainda, no teste 5, a perda de solo no SQE $\left(2.513 \mathrm{~kg} \mathrm{ha}^{-1}\right)$ foi apenas $19 \%$ maior do que no STE $\left(2.112 \mathrm{~kg} \mathrm{ha}^{-1}\right)$, significando que, no último teste de chuva, estes dois tratamentos se igualaram (estatisticamente) em termos de resistência do solo à erosão hídrica. Significa também que a energia da chuva e da enxurrada, aplicada sobre o solo durante o experimento, foi suficiente para enfraquecer a resistência do solo também no STE. Comparando os tratamentos PCE e STE, constata-se grande diferença nos valores de perda de solo. Essa diferença diminuiu progressivamente com o aumento das chuvas, a ponto de, nos testes $4 \mathrm{e} 5$, as perdas de solo não terem diferido estatisticamente entre os tratamentos, embora tenha havido grande diferença entre valores, em termos absolutos, especialmente no teste $5\left(4.069 \mathrm{~kg} \mathrm{ha}^{-1}\right.$ no PCE e $2.112 \mathrm{~kg} \mathrm{ha}^{-1}$ no STE). Assim, no teste 2, não houve perda de solo no STE, mas houve de $398 \mathrm{~kg} \mathrm{ha}^{-1}$ no PCE, enquanto no teste 3 ela foi de $171 \mathrm{~kg} \mathrm{ha}^{-1}$ no STE e de $1.148 \mathrm{~kg} \mathrm{ha}^{-1}$ no PCE, significando uma diferença de 6,7 vezes. A referida diferença foi de 2,1 vezes no teste $4\left(610 \mathrm{~kg} \mathrm{ha}^{-1}\right.$ no STE e $1.295 \mathrm{~kg} \mathrm{ha}^{-1}$ no PCE) e, no teste 5 , de $93 \%$ (2.112 kg ha ${ }^{-1}$ no STE e $4.069 \mathrm{~kg} \mathrm{ha}^{-1}$ no PCE), embora sem diferença estatística entre os tratamentos nestes dois testes. Isso demonstra, por um lado, a eficácia da semeadura direta na redução da erosão hídrica pluvial em relação ao preparo convencional, conforme já constatado por Cogo (1981), Cogo et al. (1984) e Bertol (1995), e, por outro, a progressiva redução de tal eficácia ao longo de um mês, após ambos os sistemas terem sido conduzidos por período de cinco anos e meio e, ao final, submetidos a uma escarificação e a chuvas simuladas erosivas.

Quadro 8. Perda de solo ajustada para a intensidade de chuva de $64 \mathrm{~mm} \mathrm{~h}^{-1}$ e para a declividade média das parcelas experimentais de $0,17 \mathrm{~m} \mathrm{~m}^{-1}$, durante os testes de chuva simulada, em sistemas de manejo submetidos à escarificação, em um Nitossolo Háplico alumínico

\begin{tabular}{|c|c|c|c|c|c|}
\hline Tratamento & Teste 1 & Teste 2 & Teste 3 & Teste 4 & Teste 5 \\
\hline $\mathrm{SCE}$ & $0 \mathrm{Ae}$ & $114 \mathrm{Bd}$ & $1.301 \mathrm{Ac}$ & $5.809 \mathrm{Ab}$ & $23.842 \mathrm{Aa}$ \\
\hline PCE & OAd & $398 \mathrm{Ac}$ & $1.148 \mathrm{Ab}$ & $1.295 \mathrm{BCb}$ & $4.069 \mathrm{Ba}$ \\
\hline $\mathrm{SQE}$ & OAd & oCd & $1.128 \mathrm{Ac}$ & $1.713 \mathrm{Bb}$ & $2.513 \mathrm{Ca}$ \\
\hline STE & OAd & $0 \mathrm{Cd}$ & $171 \mathrm{Bc}$ & $610 \mathrm{Db}$ & $2.112 \mathrm{Ca}$ \\
\hline
\end{tabular}

SCE: solo sem cultivo submetido à escarificação; PCE: preparo convencional submetido à escarificação; SQE: semeadura direta queimada submetida à escarificação; STE: semeadura direta tradicional submetida à escarificação. Médias seguidas da mesma letra, maiúscula na coluna e minúscula na linha, não diferem estatisticamente (Duncan, $p<0,05$ ). CV para tratamento $=5,3 \%$; CV para teste $=3,5 \%$. 
Relacionando os dados de perda de solo e os de erosividade das chuvas, o modelo exponencial do tipo $\mathrm{y}=\mathrm{ae}^{-\mathrm{bx}}$ ajustou-se aos dados para o caso do SCE, com valor de $\mathrm{R}^{2}$ significativo a $1 \%$ (Figura 3 ). Esse tipo de ajuste indica elevada degradação física do solo, ocasionada pelo contínuo preparo convencional e pela ausência de cultivo neste tratamento. Tais condições físicas do solo favoreceram o aumento do sulcamento, como constatado por Bertol (1995). Para os demais tratamentos, o modelo que melhor se ajustou aos dados foi o linear simples. Nos três tratamentos (PCE, SQE e STE), a relação dos dados de perda de solo com os de erosividade das chuvas foi significativa a $1 \%$, variando, entretanto, o coeficiente de correlação. Este coeficiente diminuiu com o aumento da consolidação do solo, ou seja, do tratamento PCE para o STE. Isso indica que a taxa de perda de solo aumentou com o aumento da erosividade das chuvas nos três tratamentos, mas foi cada vez menor com o aumento da consolidação do solo. Esse comportamento é explicado pela maior resistência do solo à erosão no STE em relação aos demais tratamentos, devido, por um lado, à permanência da cobertura do solo e, por outro, à ausência de preparo do solo no STE. Relação linear simples entre taxa de perda de solo e erosividade de chuvas simuladas também foi verificada por Cogo (1981) e Bertol (1995).

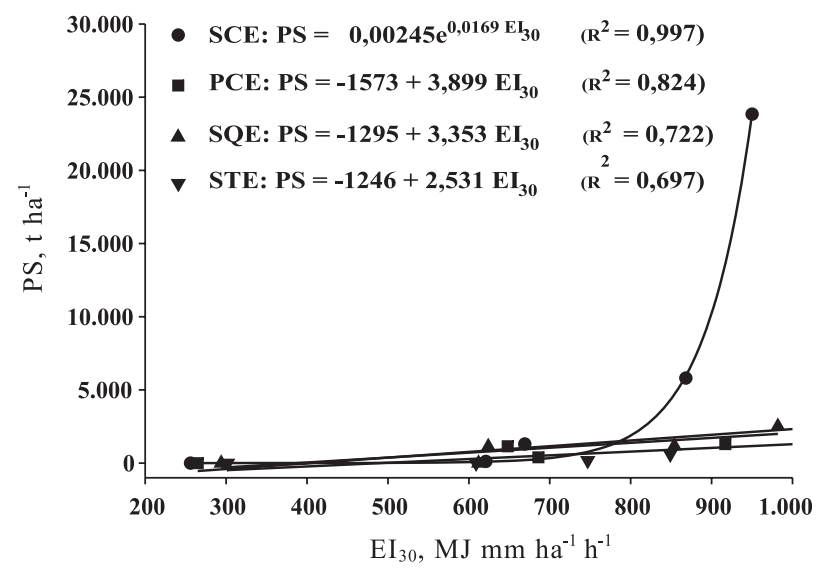

Figura 3. Relação das perdas de solo por erosão hídrica, PS, com a erosividade das chuvas simuladas aplicadas, $\mathrm{EI}_{30}$, em sistemas de manejo submetidos à escarificação, em um Nitossolo Háplico alumínico (média de duas repetições). Significativo a $1 \%$.

\section{CONCLUSÕES}

1. A rugosidade superficial do solo foi influenciada pelo tipo de preparo quando foi submetido a uma escarificação.

2. A escarificação aumentou a rugosidade em relação aos valores anteriores; o maior aumento ocorreu na semeadura direta, e o menor, no solo sem cultivo; a rugosidade diminuiu com o aumento das chuvas simuladas, com exceção do solo sem cultivo; o preparo convencional e a semeadura direta apresentaram comportamentos iguais.

3. Os tempos de empoçamento da água na superfície do solo e de início da enxurrada foram maiores na semeadura direta do que no preparo convencional e, neste, maiores do que no solo sem cultivo.

4. A infiltração de água no solo e o escoamento superficial foram influenciados pelo tipo de preparo e pelas chuvas simuladas; a semeadura direta tradicional foi o tratamento mais eficaz em aumentar a infiltração e diminuir a enxurrada.

5. A concentração de sedimentos na enxurrada e a perda de solo sofreram clara influência do tipo de preparo e do número de chuvas simuladas; os valores dessas variáveis diminuíram nos tratamentos que ocasionaram maior consolidação do solo e aumentaram com o aumento do número de chuvas.

6. O modelo exponencial do tipo $y=a e^{-b x}$ ajustouse aos dados de perda de solo e de erosividade das chuvas; para essas variáveis, no preparo convencional, na semeadura direta com resíduos queimados e na semeadura direta com resíduos mantidos, o ajuste foi possível com modelo linear do tipo $\mathrm{y}=\mathrm{a}+\mathrm{bx}$.

\section{AGRADECIMENTO}

Ao Conselho Nacional de Desenvolvimento Científico e Tecnológico - CNPq, pela bolsa de pesquisa e pelos recursos financeiros (Edital Universal 019/ 2004); à UDESC, pela bolsa (PROMOP); e ao Ministério da Educação e Ciência - MEC da Espanha, por parte dos recursos financeiros (projeto CGL2005-08219-C02-01).

\section{LITERATURA CITADA}

BERTOL, I. Comprimento crítico de declive para preparos conservacionistas de solo. Porto Alegre, Universidade Federal do Rio Grande do Sul, 1995. 185p. (Tese de Doutorado)

BERTOL, I.; AMARAL, A.J.; VÁZQUEZ, E.V.; GONZÁLEZ, A.P.; BARBOSA, F.T. \& BRIGNONI, L.F. Relações da rugosidade superficial do solo com o volume de chuva e com a estabilidade de agregados em água. R. Bras. Ci. Solo, 30:543-553, 2006.

BERTOL, I.; COGO, N.P. \& LEVIEN, R. Erosão hídrica em diferentes preparos do solo logo após as colheitas de milho e trigo, na presença e na ausência dos resíduos culturais. R. Bras. Ci. Solo, 21:409-418, 1997.

BERTOL, I.; GONZÁLEZ, A.P. \& VÁZQUEZ, E.V. Rugosidade superficial do solo sob diferentes doses de resíduo de milho submetido à chuva simulada. Pesq. Agropec. Bras., 42:103110, 2007. 
CAVALIERI, K.M.V.; TORMENA, C.A.; VIDIGAL FILHO, P.S.; GONÇALVES, A.C.A. \& COSTA, A.C.S. Efeitos de sistemas de preparo nas propriedades físicas de um Latossolo Vermelho distrófico. R. Bras. Ci. Solo, 30:137$147,2006$.

COGO, N.P. Effect of residue cover, tillage-induced roughness and slope lenght on erosion and related parameters. West Lafayette, Purdue University, 1981. 344p. (Tese de Doutorado)

COGO, N.P.; MOLDENHAUER, W.C. \& FOSTER, G.R. Soil loss reductions from conservation tillage practices. Soil Sci. Soc. Am. J., 48:368-373, 1984.

ELTZ, F.L.F. \& NORTON, D. Surface roughness changes as affected by rainfall erosivity, tillage, and canopy cover. Soil Sci. Soc. Am. J., 61: 1746-1755, 1997.

KAMPHORST, E.C.; JETTEN, V.; GUÉRIF, J.; PITKÄNEN, J. IVERSEN, B.V.; DOUGLAS, J.T. \& PAZ, A. Predicting depressional storage from soil surface roughness. Soil Sci. Soc. Am. J., 64:1749-1758, 2000.

LARSON, W.E. \& GILL, W.R. Soil physical parameters for designing new tillage systems. In: Conservation tillage. Madison, Soil Conservation Society of America, 1973. p.1322 .

MARCOLAN, A.L. \& ANGHINONI, I. Atributos físicos de um Argissolo e rendimento de culturas de acordo com o revolvimento do solo em plantio direto. R. Bras. Ci. Solo, 30:163-170, 2006.
MEYER, L.D. An investigation of methods for simulating rainfall on standard runoff plots and study of the drop size, velocity, and kinetic energy of selected spray nozzles. West Lafayette, USDA - ARS - SWCRD - ESWMRB and Purdue University, 1958. 43p. (Special Report, 81)

ONSTAD, C.A. Depressional storage on tilled soil surfaces. Trans. Am. Soc. Agric. Eng., 27:729-732, 1984.

RÖMKENS, M.J.M. \& WANG, J.Y. Effect of tillage on soil roughness. Trans. Am. Soc. Agric. Eng., 29:429-433, 1986.

SCHICK, J.; BERTOL, I.; BATISTELA, O. \& BALBINOT JÚNIOR, A.A. Erosão hídrica em Cambissolo Húmico alumínico submetido a diferentes sistemas de preparo e cultivo do solo: I. Perdas de solo e água. R. Bras. Ci. Solo, $24: 427-436,2000$

SCHWAB, G.O.; FANGMEIER, D.D.; ELLIOT, W.J. \& FREVERT, R.K. Soil and water conservation engineering. 4.ed. New York, John Wiley \& Sons, 1993. 507p.

SWANSON, N.P. Suggestions for use the rotating-boom field plot rainfall simulator to obtain data for application of the Universal Soil Loss Equation. Paraná, FAO, Nebraska University, 1965. 6p. (Relatório de consultoria)

ZOBECK, T.M. \& ONSTAD, C.A. Tillage and rainfall effects on random roughness: A review. Soil Till. Res., 9:1-20, 1987.

ZOLDAN JUNIOR, W.A. Rugosidade superficial do solo ocasionada por uma operação de escarificação aplicada após cinco anos e meio de uso de sistemas de manejo do solo, e suas relações com a erosividade da chuva e erosão hídrica em um Nitossolo Háplico. Lages, Universidade do Estado de Santa Catarina, 2006. 100p. (Tese de Mestrado) 